\title{
Informing decisions on ecosystem-based approaches for the adaptation of people in the Asia and Pacific region
}

Terry Hills ${ }^{1}$ and Emilia Pramova ${ }^{2}$

\section{Key messages}

- Key stakeholder groups in this region are generally aware of the potential of ecosystem services to reduce the impacts of climate change on people, which is often called ecosystem-based adaptation (EBA).

- Practical information on the potential and limitations of EBA is not readily available to planners and practitioners.

- An online survey confirmed the need for regional case studies and how-to guidance delivered online.

- A decision-support tool would enable stakeholders to better identify the opportunities, risks and cost effectiveness of EBA strategies in different contexts.

This brief summarises the results of a recent analysis of the awareness and information needs related to ecosystem-based approaches to adaptation in the Asia and Pacific region. These results will inform the design of a decision-support tool for development, adaptation and disaster-risk reduction stakeholders.

\section{Climate change impacts and adaptation options}

Climate change impacts are already being measured in Asia and the Pacific and are projected to increase substantially in the next 50 years (IPCC 2007).

In Asia, crop yields are declining due to rising temperatures, changes in rainfall patterns and seasonal shifts, droughts, and floods. Coastal inundations are especially affecting the heavily populated megadeltas. With increasing climate variability compounding development pressures, South and Southeast Asian countries will be subject to greater risks from flooding and exposure to other extreme events, such as tropical storms, landslides and wildfires.

Small island states in the Pacific are particularly vulnerable. Rising sea-levels, coastal inundation, seawater intrusion into freshwater lenses, soil salinisation, decline in already limited freshwater supplies, and changes in the profile of cyclones and associated storm surges will put vital ecosystems, infrastructure, settlements, and livelihood activities at risk.

1 Conservation International

2 CIFOR
Over the next 50 years, people in this region will experience cumulative increases in many climate impacts if no measures are taken (IPCC 2007). The development of incremental adaptation strategies and policies, and the implementation of 'no regret' measures and 'win-win' options will be crucial ${ }^{3}$.

\section{Ecosystem-based approaches involve the integrated} management of land, water and living resources to promote conservation and sustainable use in an equitable way (Decision 6, 5th Conference of Parties to the Convention on Biological Diversity, 2000). Such approaches can lead to 'no-regret', costefficient and effective measures that reduce people's vulnerability and climate-proof development strategies (Andrade et al. 2010; CBD 2009; TEEB 2009; WB 2009). Where these ecosystems provide services critical for human adaptation to climate change, such an approach is known as ecosystem-based adaptation (EBA). Some ecosystem services that could reduce vulnerability in the AsiaPacific context include the following.

- Mangroves can accommodate rising sea-levels and can protect coastlines from severe storms.

- Riverine and floodplain vegetation can absorb shock by delaying floods and reducing flood peaks.

- Agroforestry systems can maintain yields under climate variability as trees protect crops, provide nutrients under harsh conditions and increase overall system resilience.

Ecosystem-based adaptation can also lead to multiple social, economic and cultural co-benefits for local communities such as enhanced livelihoods and tourism (CBD 2009). Furthermore, in many localities of the Asia and Pacific region, an EBA strategy can constitute the most immediate option to be applied due to the relatively lower upfront investments and resources required in comparison to the construction and maintenance of infrastructure.

Figure 1 illustrates linkages between some of the climate change exposures common in the Asia and Pacific region, their potential

3 No-regret adaptation options minimise maladaptation risk and can be justified under all possible future scenarios, including the absence of climate change. Win-win options are measures that contribute to adaptation, biodiversity conservation, development, mitigation and poverty reduction. They can be justified even in the absence of climate change. 


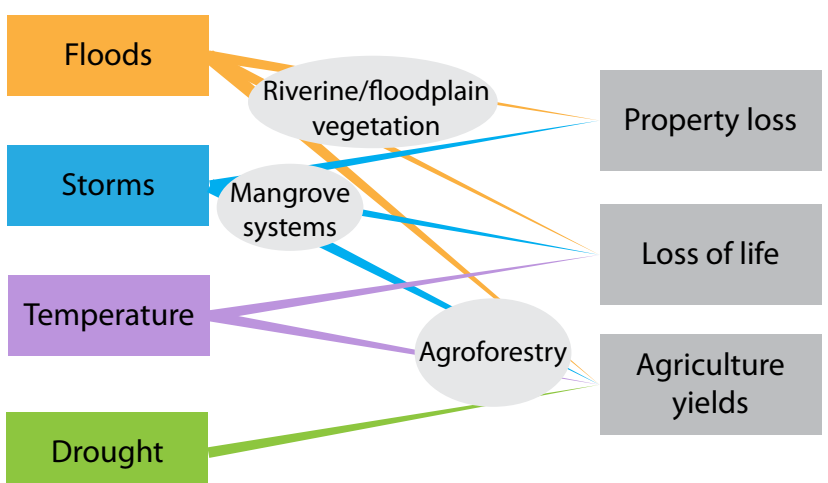

Figure 1. Climate change risks, ecosystem buffers and impact area examples

impacts, and the role of specific ecosystem types in absorbing some of the impact.

\section{Informing decisions for action}

Managing ecosystems through integrated planning for the adaptation of people to climate change is an emerging approach that is not yet fully understood. Many misconceptions exist regarding its potential and its limitations. Although there is a growing consensus that using natural assets is an important part of 'climate proofing' human development, investment in EBA approaches still represents a small portion of adaptation activity in the Asia and Pacific regions and elsewhere (Pramova et al. 2011).

Evidence-based knowledge in relevant disciplines (hydrology, disaster risk reduction, coastal management) is significant and continuously growing yet often fragmented and poorly coordinated, even among the various existing adaptation knowledge platforms. There is a frequently disconnect between the lessons generated through EBA-relevant research and implementation and the information needs of decision makers and practitioners in development and adaptation planning. Practical information on the potential and limitations of different EBA approaches within different contexts is not consolidated or made available in user-friendly formats.

This brief describes the needs related to this information and the potential formats of a decision-support tool that will enable stakeholders in the Asia and Pacific region to have access to consolidated information for identifying EBA opportunities, and designing and implementing EBA options within broader adaptation planning and risk management.

\section{Analysing user needs}

The main users of a decision-support tool would be advisers to decision makers from national and subnational planning, development, adaptation and disaster risk reduction (DRR) departments. Other key users would include those responsible for project design, monitoring and evaluation in adaptation and
DRR. Both stakeholder groups would benefit from an increased awareness of the practical advantages and limitations of EBA in the context in which they operate.

An online survey was conducted between 18 April and 25 May 2011 to understand better the most appropriate approaches for ensuring that EBA is among the options considered during planning processes in diverse Asia-Pacific contexts.

Additional insights were gained from another survey conducted during the Pacific Climate Change Roundtable of March 2011 in Niue; discussions during the EBA training implemented for the Asia region by Wetlands International, WWF and Conservation International in Orissa, India (August 2010); and an evaluation of the main adaptation knowledge portals by WWF.

The aggregated results presented here are based on the online survey, but issues raised through the other information sources are also discussed.

The 192 online survey respondents demonstrate a reasonable geographic representation of the target audience, namely developing countries in the Asia and Pacific region. Thirty respondents were from other areas, including Australia and New Zealand. Representation from Central and West Asia was minimal, so any conclusions may not be relevant beyond Southeast and South Asia and the Pacific.

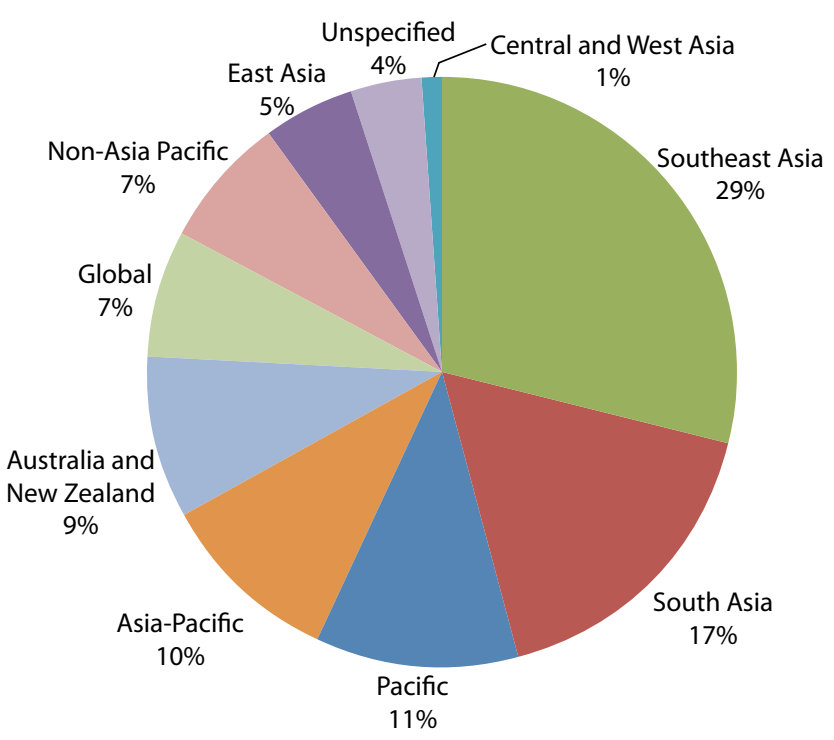

Figure 2. Survey respondents (192) in the Asia and Pacific region, by subregion of work

\section{Survey results about awareness and information needs}

Online survey respondents were predominantly concerned with 4 categories of climate-related hazards: droughts, floods, sea-level rise and storms and cyclones. Stakeholders would best benefit from a decision-support tool that prioritises these 
Which aspects of climate change are most relevant to your responsibilities? (can select more than one)

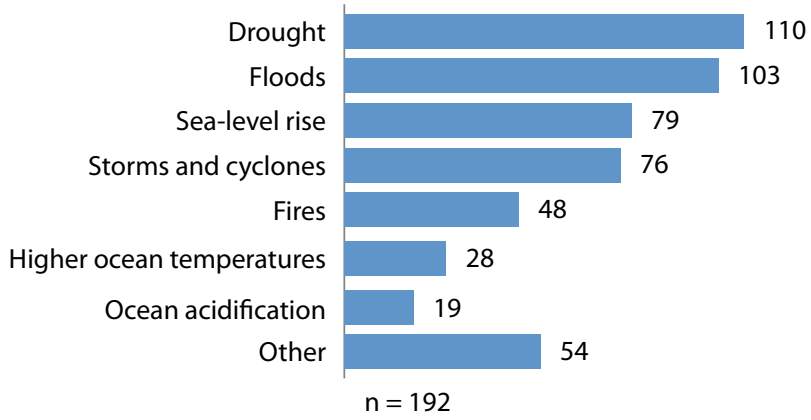

Figure 3. Respondents' priority concerns related to climate hazards and effects

aspects. This corresponds well with the relative significance of these hazards in terms of mortality risk distribution in the region (UNISDR 2011).

A significant number of people surveyed selected the category 'other' which confirms the diversity of perceptions and concerns relating to climate change. Often mentioned 'other' responsibilities included glacial melt, loss of coastal or forest vegetation, landslides and saline infiltration or intrusion.

When asked about sectoral impacts, respondents considered ecosystems and biodiversity, livelihoods, and agriculture the three most significant issues. For identifying priorities for the decision-support tool, these three impact areas could be presented in an integrated manner given the relationships among them. Respondents expressed limited interest in impacts on human health, fisheries and infrastructure and settlements, although all are expected to intensify significantly in the region. Awareness-raising and introductory resources on these impacts and the role of ecosystem services might be a useful component in the decision-support tool.

The majority of respondents (77\%) said they believe that ecosystem services can reduce the impacts of climate change on people in the context of their work. This suggests a reasonably strong awareness of the potential of EBA, but, since $21 \%$ of respondents indicated that they 'don't know', additional awareness-raising and introductory resources are justified.

In response to the question 'What are the main sources of information that you currently use to support decision-making in this area?' there was a clear cluster of four most widely used resources: colleagues, vulnerability assessment documents, socio-economic and ecological data, and databases of international organisations such as the World Bank, United Nations Environment Programme and the Intergovernmental Panel on Climate Change. Discussions during the EBA training also emphasised that vulnerability assessments and economic valuation should be priorities for integration into tools, given their capacity to 'convince and communicate' and to guide effective decision making.

When asked which types of information would be most useful, the majority of the respondents to the online survey selected in-region case studies. This was consistent with the needs expressed by EBA training participants and the Pacific pilot survey, confirming that a decision-support tool with a strong

What kind of information or tools would be most useful for decision-making related to the role of ecosystem services in supporting climate change adaptation? (can select up to 4)

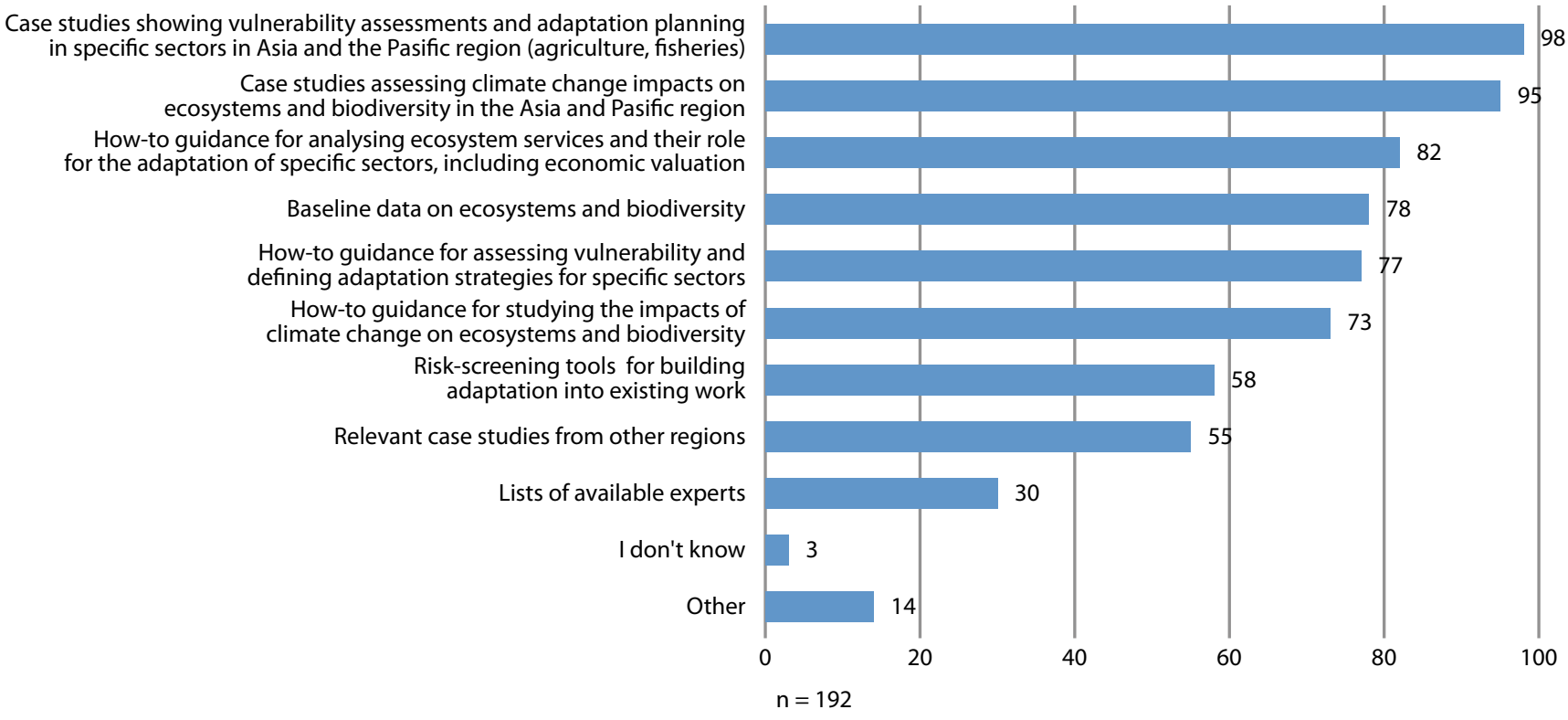

Figure 4. Online survey results showing preferred information for decision making related to EBA 
case study component would be advantageous. Practical howto guidance was also highly regarded by both the online survey respondents and the EBA training participants; online survey participants also said baseline data was important. To deliver and share information most respondents said they preferred online formats including online training. The most appropriate tool would be available online.

Despite this preference, about one-third of the respondents reported that they had not used any of the popular online knowledge platforms such as weADAPT (www.weadapt.org), Asia-Pacific Adapt (www.asiapacificadapt.net) or Adaptation Learning Mechanism (www.adaptationlearning.net), suggesting that the decision-support tool should be available in different formats and also accompanied by an awareness-raising programme about existing platforms.

\section{Components of a decision-support tool}

A decision-support tool should aim to deliver hazardspecific, practical information on EBA strategies that will enable stakeholders to identify the opportunities, risks, costeffectiveness and capacity needs associated with the planning and implementation of the different strategies and to make comparative assessments between adaptation solutions (Figure 1). Tool information should allow stakeholders to better consider and analyse options in their local context and also compare them against engineering alternatives, offering a clear comparative advantage over existing tools. A strong focus should be made on case studies and adaptation projects already implemented, whose effectiveness will be evaluated for the purposes of this tool. Current state of knowledge and biodiversity data that are relevant for different EBA options should be consolidated from peer-reviewed and grey literature from projects, institutions and initiatives.

Based on the information gathered, we recommend that all information be organised and presented primarily online, with options for filtering by categories of risk, strategies and locations, among others. Such tools can easily be hosted by one of the existing adaptation knowledge platforms. Other formats for presenting and delivering the information of a decisionsupport tool can also be explored, including as a desktop tool or book.

\section{Acknowledgements}

This work is a joint initiative between Conservation International and CIFOR. It was made possible through contributions from Wetlands International, WWF US, and the Secretariat for the Pacific Regional Environment Programme.

\section{References}

Andrade Pérez, A., Herrera Fernandez, B. and Cazzolla Gatti, R. 2010 Building resilience to climate change: ecosystem-based adaptation and lessons from the field. International Union for the Conservation of Nature, Gland, Switzerland.

Convention on Biological Diversity (CBD) 2009 Connecting biodiversity and climate change mitigation and adaptation: report of the second ad hoc technical expert group on biodiversity and climate change. Technical Series No. 41. CBD, Montreal, Canada.

Intergovernmental Panel on Climate Change (IPCC) 2007 Climate change 2007: synthesis report. Contribution of Working Groups I, II and III to the Fourth Assessment Report of the Intergovernmental Panel on Climate Change. Fourth Assessment Report. IPCC, Geneva, Switzerland.

Pramova, E., Locatelli, B., Brockhaus, M. and Fohlmeister, S. [forthcoming] Ecosystem services in the national adaptation programmes of action. Climate Policy.

United Nations Environment Programme 2009 The economics of ecosystems and biodiversity for national and international policy makers - summary: responding to the value of nature. UNEP, Wesseling, Germany.

United Nations International Strategy for Disaster Reduction Secretariat (UNISDR) 2011 Revealing risk, redefining development. Global assessment report on disaster risk reduction. UNISDR, Oxford, UK. http://www.unisdr.org/we/inform/publications/19846 (October 2011).

World Bank 2009 Convenient solutions to an inconvenient truth: ecosystem-based approaches to climate change. World Bank, Washington, DC.

\section{For more information}

This work is currently under development. For more information, or contributions of case studies, project information or other relevant data, please contact Terry Hills at t.hills@conservation.org or Emilia Pramova at e.pramova@cgiar.org. 